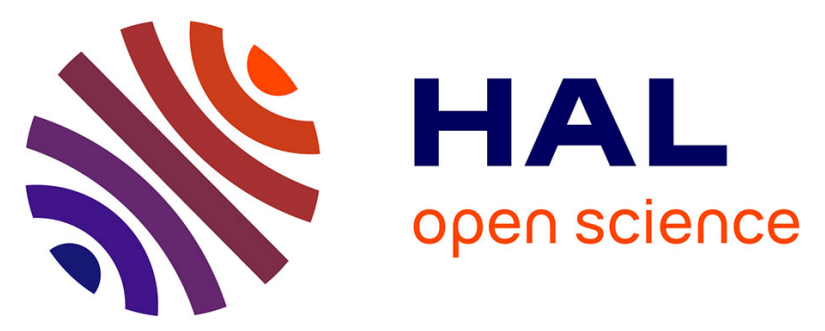

\title{
FRET imaging approaches for in vitro and in vivo characterization of synthetic lipid nanoparticles
}

Julien Gravier, Lucie Sancey, Samuli Hirsjärvi, Emilie Rustique, Catherine

Passirani-Malleret, Jean-Pierre Benoit, Jean-Luc Coll, Isabelle Texier

\section{To cite this version:}

Julien Gravier, Lucie Sancey, Samuli Hirsjärvi, Emilie Rustique, Catherine Passirani-Malleret, et al.. FRET imaging approaches for in vitro and in vivo characterization of synthetic lipid nanoparticles. Molecular Pharmaceutics, 2014, 11 (9), pp.3133-44. 10.1021/mp500329z . hal-03178914

\section{HAL Id: hal-03178914 \\ https://univ-angers.hal.science/hal-03178914}

Submitted on 24 Mar 2021

HAL is a multi-disciplinary open access archive for the deposit and dissemination of scientific research documents, whether they are published or not. The documents may come from teaching and research institutions in France or abroad, or from public or private research centers.
L'archive ouverte pluridisciplinaire HAL, est destinée au dépôt et à la diffusion de documents scientifiques de niveau recherche, publiés ou non, émanant des établissements d'enseignement et de recherche français ou étrangers, des laboratoires publics ou privés. 


\section{FRET Imaging Approaches for in Vitro and in Vivo Characterization of Synthetic Lipid Nanoparticles}

Julien Gravier, ${ }^{\dagger, \neq, \delta, \|, \perp}$ Lucie Sancey, ${ }^{\S, \|, \perp}$ Samuli Hirsjärvi,,$\#$, Em Emilie Rustique, ${ }^{\dagger, \ddagger}$ Catherine Passirani, ${ }^{\#, \Phi[}$

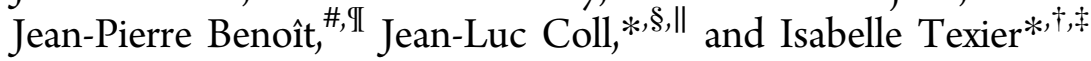

${ }^{\dagger}$ Université Grenoble Alpes, F-38000 Grenoble, France

${ }^{\ddagger}$ CEA-LETI MINATEC/DTBS, 17 avenue des Martyrs, F-38054 Grenoble Cedex 9, France

${ }^{\S}$ INSERM U823, Institut Albert Bonniot, 38706, La Tronche Cedex, France

"Université Joseph Fourier, BP 53, Grenoble, France

${ }^{\#}$ Micro et Nanomédecines Biomimétiques, LUNAM Université, F-49933 Angers, France

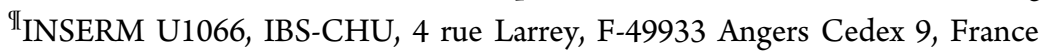

Supporting Information

ABSTRACT: DiI and DiD, two fluorophores able to interact by FRET (Förster resonance energy transfer), were coencapsulated in the core of lipid nanocapsules (LNCs) and nanoemulsions (LNEs), lipophilic reservoirs for the delivery of drugs. The ability of FRET imaging to provide information on the kinetics of dissociation of the nanoparticles in the presence of bovine serum albumin (BSA) or whole serum, or after incubation with cancer cells, and after systemic administration in tumor-bearing mice, was studied. Both microscopic and macroscopic imaging was performed to determine the behavior of the nanostructures in a biological environment. When $2 \mathrm{mg} / \mathrm{mL}$ FRET LNEs or LNCs were dispersed in buffer, in the presence of unloaded nanoparticles, BSA, or in whole serum, the presence of serum was the most active in destroying the particles. This occurred immediately with a diminution of $20 \%$ of FRET, then slowly, ending up with still $30 \%$ intact nanoparticles at $24 \mathrm{~h}$. LNCs were internalized rapidly in cultured cells with the FRET signal decreasing within the first minutes of incubation, and then a plateau was reached and LNCs remained intact during $3 \mathrm{~h}$. In contrast, LNEs were poorly internalized and were rapidly dissociated after internalization. Following their iv injection, LNCs appeared very stable in subcutaneous tumors implanted in mice. Intact particles were found using microscopic FRET determination on tumor sections $24 \mathrm{~h}$ after injection, that correlated well with the $8 \%$ calculated noninvasively on live animals. FRET investigations showed the potential to determine valid and reliable information about in vitro and in vivo behavior of nanoparticles.

KEYWORDS: FRET, lipid nanoparticles, fluorescence imaging, in vivo imaging, confocal microscopy

\section{INTRODUCTION}

Nanosized particles and vectors have gained a strong interest for medical applications (imaging, drug delivery, tissue engineering) in recent decades. ${ }^{1-3}$ The fate of these nanoobjects in biological systems is still difficult to assess, although tools for their physicochemical characterizations are now well developed (size and charge analysis, microscopy characterizations using techniques such as TEM and AFM, and spectroscopic characterizations using techniques such as FTIR and NMR). Currently, in vivo tracking of inorganic particles such as iron oxide nanocrystals or quantum dots can be directly performed due to their intrinsic magnetic or luminescent signals, or by their element quantitation. In contrast, the study of the in vivo fate of organic nanoparticles requires their labeling by a contrast agent. Labeling agents can be radioactive elements $\left({ }^{3} \mathrm{H},{ }^{14} \mathrm{C},{ }^{18} \mathrm{~F}, \ldots\right)$ but also bulkier entities such as fluorescent or magnetic tags. It is expected that the labeled particle will function as similarly as possible to the unlabeled particle. However, it is well-known that this may not always be true, and that different biodistributions may be observed when different tags are used to label the same nano-object, indicative of its in vivo instability, dissociation, or metabolization.

In vivo fluorescence imaging is a relatively recent, real-time, noninvasive, and radiation-free technology, now routinely performed in rodents. ${ }^{4-6}$ It has been used to track the fate of inorganic or organic nanocarriers, such as liposomes, ${ }^{7}$ lipoproteins, ${ }^{8,9}$ polymers, ${ }^{10,11}$ silica, ${ }^{12-14}$ calcium phosphate, ${ }^{15,16}$ or oxide ${ }^{17}$ nanoparticles. Fluorescence imaging also presents the advantage of being a multiscale technique, from in vivo

Received: $\quad$ May 4, 2014

Revised: July 17, 2014

Accepted: August 6, 2014

Published: August 6, 2014 
whole-body imaging down to microscopy analysis at the cellular level of the collected tissues. FRET (Förster resonance energy transfer) imaging has been used for decades to address different biological issues such as the measurement of distance during molecular interactions, protein folding, or lipid membrane dynamics. ${ }^{18-20}$ FRET is a nonradiative energy transfer process, based on the interactions between spatially close (2 to $10 \mathrm{~nm}$ ) donor and acceptor fluorophores. ${ }^{19}$ FRET occurs whenever the donor fluorophore emission spectrally overlaps with the acceptor absorption. This results in a decrease of the fluorescence lifetime and quantum yield of the donor in the presence of the acceptor. Importantly, this interaction decays very rapidly with the donor-acceptor distance $R$ (FRET efficiency $\left.E_{\mathrm{FRET}} \propto 1 / R^{6}\right)$, making FRET imaging a "nanoscale ruler". Therefore, in vivo FRET imaging should constitute a radioactive-free technique of choice to gain information on the behavior of organic nanocarriers in animal models, especially on their stability while circulating in blood, their distribution in organs, and spatiotemporal degradation kinetics.

We recently compared the influence of composition, size, and surface coating on the biological properties of two families of synthetic lipid-core nanoparticles, lipid nanocapsules (LNCs), and lipid nanoemulsions (LNEs). ${ }^{21}$ Their in vitro complement activation and in vivo biodistribution assessed by the encapsulation of a lipophilic cyanine, DiD, were studied. Similar biodistribution patterns were observed for both nanoparticles and all sizes explored in the 25-100 nm range. Patterns observed included weak liver accumulation, no significant spleen uptake, important lymph node labeling, and tumor accumulation in different models due to the enhanced permeability and retention (EPR) effect. The kinetics and biodistribution patterns were completely different from that of the free $\mathrm{DiD}$ fluorophore, demonstrating that the results reflected the kinetics and organ distribution of the nanocarriers. However, limited information was obtained on the dissociation kinetics of the nanoparticles in mice or at the cellular level.

In the present study, we coencapsulated two fluorophores able to interact by FRET in the lipid-core of LNC and LNE nanoparticles. We focused on core encapsulation, since these nanoparticles are particularly interesting for the large volume of their lipid reservoir, suitable for elevated payload transportation of hydrophobic drugs, ${ }^{22-26}$ complexed DNA, ${ }^{27,28}$ radiotherapeutics, $^{29,30}$ and imaging agents. ${ }^{31-33}$ It was expected that coencapsulated fluorophores would mimic the in vivo distribution of drugs with similar lipophilic properties, whereas the recording of their FRET interaction would give information on their kinetics of release from the lipid nanocarriers. Using this approach, when a FRET signal is recorded, both fluorophores are at close proximity in the core of the intact lipid nanoparticles. The decrease of FRET signal would indicate the dissociation of the particle core, with release of the drugmodel fluorophores. In this report, we first carried out a photochemical study to design DiI/DiD FRET pair-labeled lipid nanocarriers with optimized fluorophore ratios. The cellular uptake of the FRET LNCs and LNEs was then studied in vitro in a cancer cell model. Finally, in vivo imaging in nude mice carrying subcutaneous human tumors was performed after intravenous administration of FRET labeled nanoparticles.

\section{EXPERIMENTAL SECTION}

2.1. Materials. Solutol HS15 (PEG 660 12-hydroxystearate) was a gift from BASF (Ludwigshafen, Germany). Myrj S40 (PEG 40 stearate, $1980 \mathrm{Da}$ ) and Super Refined Soybean
Oil were obtained from Croda Uniquema (Chocques, France). Labrafac WL 1349 (caprylic/capric acid triglycerides) and Suppocire NB were bought from Gattefossé S.A. (Saint-Priest, France), and Lipoid S75-3 (lecithin with more than 75\% phosphatidylcholine) was bought from Lipoid $\mathrm{GmbH}$ (Ludwigshafen, Germany). Milli-Q185 water (Waters, Saint-Quentinen-Yveline, France) was used in all experiments. The fluorescent dyes, DiI (1,1'-dioctadecyl-3,3,3', $3^{\prime}$-tetramethylindocarbocyanine perchlorate) and $\mathrm{DiD}\left(1,1^{\prime}\right.$-dioctadecyl$3,3,3^{\prime}, 3^{\prime}$-tetramethylindodicarbocyanine perchlorate), were obtained from Invitrogen (Cergy Pontoise, France). All other reagents were of analytical grade.

2.2. Nanoparticle Preparation. $50 \mathrm{~nm}$ diameter lipid nanoparticles were prepared according to previously described procedures. $^{21}$ The phase inversion temperature method was used for LNC production, according to Heurtault et al. ${ }^{34}$ Solutol (282 mg), Lipoid (25 mg), Labrafac (343 mg), NaCl $(30 \mathrm{mg})$, and water $(987 \mathrm{mg}$ ) were mixed, and DiI and DiD fluorescent dyes in acetone were added to this mixture in the desired amounts. Acetone was evaporated by heating at $60{ }^{\circ} \mathrm{C}$ for $10 \mathrm{~min}$ under stirring. The formulation was heated to $85^{\circ} \mathrm{C}$ at a rate of $5{ }^{\circ} \mathrm{C} / \mathrm{min}$ followed by cooling at the same rate to 65 ${ }^{\circ} \mathrm{C}$. This cycle was repeated twice. During the last decrease of temperature, at $78{ }^{\circ} \mathrm{C}$ (during the phase inversion zone), the system was diluted with $4.2 \mathrm{~mL}$ of cold $\left(4{ }^{\circ} \mathrm{C}\right)$ water, leading to formation of stable LNCs. LNEs were prepared by the method described by Gravier et al. ${ }^{33}$ Appropriate dye amounts in $\mathrm{CH}_{2} \mathrm{Cl}_{2}$ were poured into a $5 \mathrm{~mL}$ vial. The solvent was evaporated under vacuum before the oil premix $(85 \mathrm{mg}$ of soybean oil, $255 \mathrm{mg}$ of Suppocire NB, and $65 \mathrm{mg}$ of Lipoid) was added. $345 \mathrm{mg}$ of Myrj S40 was dissolved in $154 \mathrm{mM} \mathrm{NaCl}$ aqueous solution (qsp $2 \mathrm{~mL}$ ) and added to the oily premix. The mixture was placed in a $60{ }^{\circ} \mathrm{C}$ water bath and sonicated for 5 min using a VCX750 Ultrasonic processor (power output 190 $\mathrm{W}$, probe diameter $3 \mathrm{~mm}$, Sonics, Newtown, CT, USA). LNEs were dialyzed overnight at room temperature against an aqueous buffer (12-14 kDa molecular weight cutoff membranes, ZelluTrans, Roth, France). At the end of the preparation, LNC and LNE dispersions were filtered through $0.22 \mu \mathrm{m}$ filters.

2.3. Physicochemical Characterizations. Proper size and size distribution (polydispersity index) of the nanoparticles were checked by photon correlation spectroscopy (Malvern Zetasizer ZS, Worcestershire, U.K.) in $0.1 \times$ PBS ( $1 \mathrm{mM}$ phosphate, $15.4 \mathrm{mM} \mathrm{NaCl}, \mathrm{pH}$ 7.2). Emission and absorbance spectra were recorded respectively using a PerkinElmer LS50B fluorimeter and a Cary 300 Scan spectrophotometer (Varian) with $1.5 \mathrm{~mL}$ samples placed in disposable cuvettes. Dye concentrations mentioned in the physicochemical studies refer to local dye concentration inside the LNC and LNE particle core, assuming that dye encapsulation efficiency is $>95 \%{ }^{33}$ (local concentrations in the millimolar range). Typical concentrations of $10 \mu \mathrm{M}$ in dyes $(1-5 \mathrm{mg} / \mathrm{mL}$ of lipids) are used for measurements. For bovine serum albumin (BSA) and bovine serum stability studies, $0.2 \% \mathrm{w} / \mathrm{w}$ solutions of FRET nanoparticles $(2 \mathrm{mg} / \mathrm{mL}$ of total lipids (oil, wax, phospholipids, and PEG surfactants), $5 \mu \mathrm{M}$ in DiI, DiD:DiI = 4:1) were prepared and incubated at $37^{\circ} \mathrm{C}$ in either $1 \times$ PBS buffer, PBSBSA buffer $(40 \mathrm{mg} / \mathrm{mL}$ of BSA in $1 \times$ PBS $)$, or bovine serum (Gibco). The lipid concentration was set to reflect the one used for in vivo experiments, according to the number of intravenously injected nanoparticles $(200 \mu \mathrm{L}$ at $20 \mathrm{mg} / \mathrm{mL}$ of lipids) and the total mouse blood volume $(2 \mathrm{~mL})$. At indicated 
times, $50 \mu \mathrm{L}$ of solutions were taken and diluted in $150 \mu \mathrm{L}$ of distilled water before absorbance and fluorescence measurements were carried out in a 96-well plate (Beckton-Dickinson, Le Pont de Claix, France) using a microplate reader (Tecan, Lyon, France).

2.4. Cell Confocal Microscopy. HEK293 $\left(\beta_{3}\right)$ cells, HEK293 cells stably transfected with human $\beta_{3}$ integrin (kindly provided by J.-F. Gourvest, Aventis, France) were cultured at $37{ }^{\circ} \mathrm{C}$ in a humidified $95 \%$ air/5\% $\mathrm{CO}_{2}$ atmosphere before growing in a 4-well Lab-Tek I chambered coverglass as previously described. ${ }^{35}$ Cell medium was replaced by DMEM without FBS for $10 \mathrm{~min}$ before addition for different duration of LNC or LNE nanoparticles, with a total of $1 \mu \mathrm{M} \mathrm{DiD}(0.4$ $\mathrm{mg} / \mathrm{mL}$ of lipids, DiD:DiI 4:1). After incubation, medium was removed and replaced by clear DMEM without red phenol, without FBS, and cells were analyzed at $37{ }^{\circ} \mathrm{C}, 5 \% \mathrm{CO}_{2}$.

Cell imaging was performed on an Axiovert 200 LSM510 LNO Meta microscope (Carl Zeiss, Lena, Germany), using a $40 \times$ oil immersion objective of 1.2 numerical aperture. During the experiment, the pinhole diameter was fixed at $84 \mu \mathrm{m}$ to allow confocal slides thickness $<1.2 \mu \mathrm{m}$. For FRET signal, the nanocarriers were excited with the $543 \mathrm{~nm}$ laser (11\% power) and fluorescence collected from 640 to $704 \mathrm{~nm}$. DiI signal was obtained after excitation at $543 \mathrm{~nm}$ (11\% power) and collected from 560 to $615 \mathrm{~nm}$. DiD signal was obtained after excitation at $633 \mathrm{~nm}$ (5\% power) and collected from 640 to $704 \mathrm{~nm}$.

2.5. In vivo Images. Female NMRI nude mice (6-8 weeks, Janvier, Le Genest-Saint-Isle, France) were injected subcutaneously with $5 \times 10^{6}$ mouse mammary carcinoma TS/A-pc cells. TS/A-pc cells were cultured at $37{ }^{\circ} \mathrm{C}$ in a humidified $95 \%$ air/5\% $\mathrm{CO}_{2}$ atmosphere in RPMI 1640 supplemented with $1 \%$ glutamine, $10 \%$ fetal bovine serum (FBS), $25 \mathrm{nM} \mathrm{2-}$ mercaptoethanol, 50 units $/ \mathrm{mL}$ penicillin, and $50 \mu \mathrm{g} / \mathrm{mL}$ streptomycin. ${ }^{36}$ After tumor growth (2 weeks), anesthetized mice (isoflurane/oxygen $3.5 / 4 \%$ for induction and $1.5 / 2 \%$ thereafter, CSP, Cournon, France) were injected in the tail vein with $200 \mu \mathrm{L}$ of a solution of FRET nanoparticles $(10 \mathrm{nmol}$ of DiI, $4 \mathrm{mg}$ of lipids, DiD:DiI 4:1). Fluorescence images were then acquired using an IVIS kinetic fluorescence imager (Caliper Life Science, Hopkinton, MA, USA) at different time points after mice were anesthetized. The DiI channel used $535 \mathrm{~nm}$ excitation and recorded fluorescence at $640 \mathrm{~nm}( \pm 10$ $\mathrm{nm})$. The DiD channel used $633 \mathrm{~nm}$ excitation and recorded emission at $680 \mathrm{~nm}( \pm 10 \mathrm{~nm})$. FRET channel was defined as using the $535 \mathrm{~nm}$ excitation and collecting emission at $680 \mathrm{~nm}$ $( \pm 10 \mathrm{~nm})$. To allow the quantification of the percentage of FRET, a calibration curve was established, using different mixes containing $100 \%$ to $0 \%$ FRET nanoparticles (Figure S4 in the Supporting Information); the 0\% FRET mix contained 100\% of nanocarriers containing the donor and the acceptor in different particles.

2.6. Ex Vivo Images. After mice were sacrificed and tissue was collected, $7 \mu \mathrm{m}$ width tumor sections were analyzed with a Zeiss LSM 710 NLO confocal microscope (Carl Zeiss, Germany) using a $40 \times$ oil immersion objective of $1 \mathrm{NA}$ (optical slices $1 \mu \mathrm{m}$ ) and the Zen software, immediately after Mowiol mounting. DiI was excited at $543 \mathrm{~nm}$ with a DPSS 560 $\mathrm{nm}$ laser $(0.6 \%)$ and its emission collected at 550-600 $\mathrm{nm}$ to reduce spectral cross-talk. $\mathrm{DiD}$ was excited with a $\mathrm{HeNe} 633$ $\mathrm{nm}$ laser (2\%) and its emission collected at 670-748 $\mathrm{nm}$. FRET was recorded using excitation at $543 \mathrm{~nm} \mathrm{(9 \% )} \mathrm{and}$ fluorescence collected at 670-748 nm. Optical slides were 1.2 $\mu \mathrm{m}$ thickness, with a 1.1 digital gain and a pinhole diameter of
$41.8 \mu \mathrm{m}$. Similarly to in vivo image processing, calibration curves were established using different mixes containing $100 \%$ to $0 \%$ FRET nanoparticles to link the \% of intact FRET nanoparticles to either the $\mathrm{DiD} / \mathrm{DiI}$ fluorescence ratio or the FRET $_{\text {ratio }}$ (see below).

2.7. FRET Calculation for Physicochemical Studies. Förster resonance energy transfer (FRET) efficiency is the fraction of photons absorbed by the donor that are transferred to the acceptor. ${ }^{20}$ FRET efficiency $E_{\text {FRET }}$ strongly depends of the distance $R$ between the donor and acceptor, as indicated by eq 1 , in which $R_{0}$ stands for the Förster radius, which corresponds to the distance at which transfer efficiency is $50 \%$. $R_{0}$ depends on the spectral overlap between emission of the donor and absorbance of the acceptor. It is constant for a given donor/acceptor pair and can be calculated as detailed in the Supporting Information. For the DiI/DiD FRET pair, $R_{0}=5.2$ nm.

$$
E_{\mathrm{FRET}}(R)=\frac{R_{0}{ }^{6}}{R^{6}+R_{0}{ }^{6}}
$$

Experimentally, FRET efficiency can be calculated measuring the relative fluorescence intensity of the donor, in the absence or in the presence of the acceptor. ${ }^{20}$ In this study, in order to take into account possible small variations of dye and particle concentration among samples, fluorescence intensities were normalized using absorbance measurements, and experimental FRET efficiencies were calculated as described below. First, absorption and emission spectra of DiI-loaded LNCs and LNEs ( $A_{\mathrm{D}}$ and $F_{\mathrm{D}}$ respectively) and DiD-loaded LNCs and LNEs $\left(A_{\mathrm{A}}\right.$ and $F_{\mathrm{A}}$ respectively) were measured. Absorption spectra were corrected from scattering (see the Supporting Information). Scattering-corrected absorption spectra $\left(A_{\mathrm{FRET}}\right)$ and emission spectra $\left(F_{\mathrm{FRET}}\right.$, at donor excitation wavelength, i.e., $510 \mathrm{~nm}$ for $\mathrm{DiI} / \mathrm{DiD}$ ) of the FRET nanoparticles were then fitted using the reference spectra obtained with donor and acceptor alone, according to eqs 2 and 3 :

$$
\begin{aligned}
& A_{\text {FRET }}=x_{\mathrm{D}} A_{\mathrm{D}}+x_{\mathrm{A}} A_{\mathrm{A}} \\
& A_{\text {FRET }}=y_{\mathrm{D}} F_{\mathrm{D}}+y_{\mathrm{A}} F_{\mathrm{A}}
\end{aligned}
$$

where $A_{\mathrm{FRET}}, A_{\mathrm{D}}$, and $A_{\mathrm{A}}$ are absorption spectra of FRET and donor and acceptor samples respectively; $x_{\mathrm{D}}$ and $x_{\mathrm{A}}$ are the fitting terms associated with donor and acceptor spectra. $F_{\mathrm{FRET}}$, $F_{D}, F_{A}$ are the fluorescence spectra and $y_{D}$ and $y_{A}$ the variable parameters associated with donor and acceptor spectra. Experimental FRET efficiency was then calculated according to eq 4:

$$
E=1-\frac{y_{\mathrm{D}}}{x_{\mathrm{D}}}
$$

Experimental values were compared to theoretical values obtained by a very simple predictive model, assuming that the donor is in an infinite solution of soybean oil (refractive index of 1.47), representing the oily core, and containing a homogeneous density of acceptors at a defined concentration. With this model, FRET efficiency is given by eq 5 ,

$$
\begin{gathered}
E(\gamma)=\sqrt{\pi} \gamma e\left(\gamma^{2}\right)(1-\operatorname{erf}(\gamma)) \quad \text { with } \\
\operatorname{erf}(x)=\frac{2}{\sqrt{\pi}} \int_{0}^{x} e\left(-t^{2}\right) \mathrm{d} t
\end{gathered}
$$




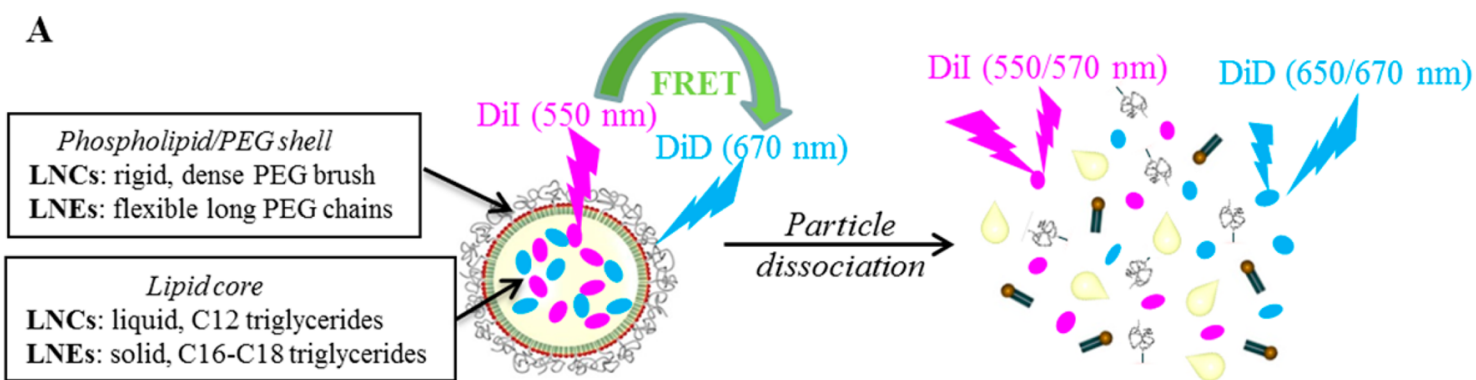

B

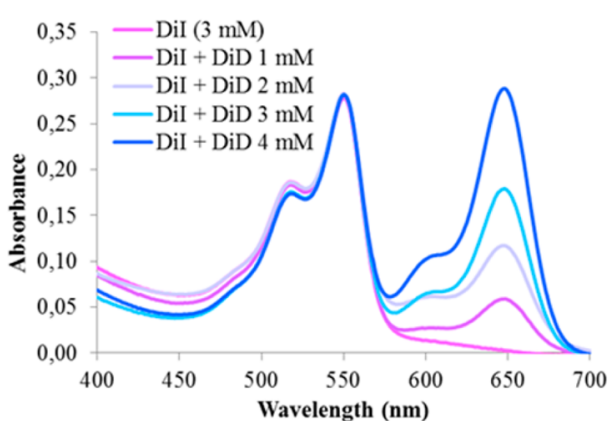

D

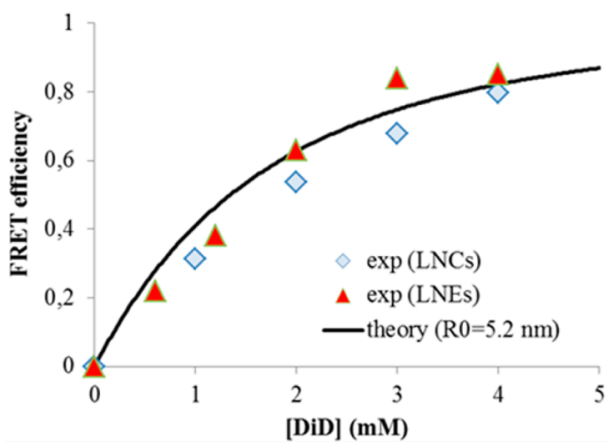

C

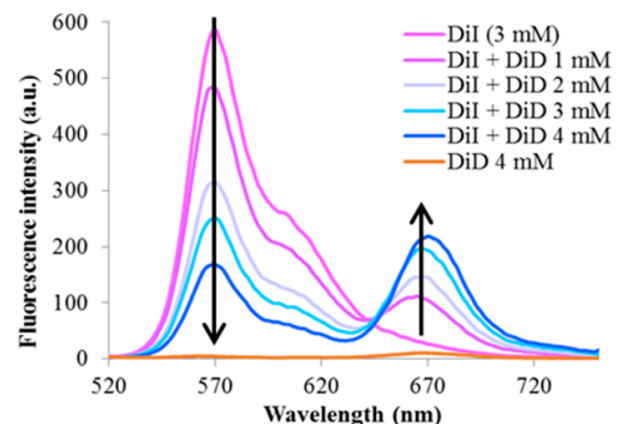

$\mathbf{E}$

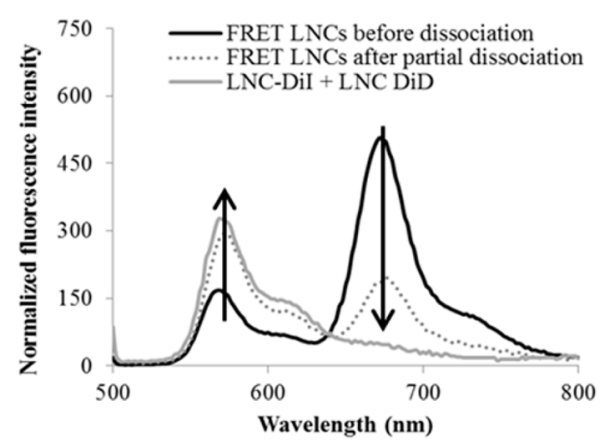

Figure 1. Structure and photochemical characterization of DiI/DiD FRET lipid nanoparticles. (A) Schematic representation of the particles and the FRET process. (B) Absorbance spectra of FRET LNCs. (C) Fluorescence spectra of FRET LNCs (excitation at $490 \mathrm{~nm}$, in the DiI absorption band). (D) Experimental and calculated FRET efficiency for LNCs and LNEs. (E) Loss of FRET signal and DiI fluorescence recovery upon particle dissociation in the presence of DMSO (excitation at $490 \mathrm{~nm}$, in the DiI absorption band).

for which $\gamma=A / A_{0}, A_{0}=447 / R_{0}^{3}\left(R_{0}\right.$ being expressed in $\AA$ ), $A$ being the acceptor concentration. ${ }^{20}$

2.8. FRET Calculation for in Vitro and in Vivo Experiments. FRET was quantified in in vitro and in vivo images using the acceptor (DiD) over donor (DiI) fluorescence ratio $\left(A / D_{\text {ratio }}\right)$, each recorded in its wavelength range. For in vivo experiments, donor and acceptor signals were corrected from autofluorescence background measured before particle injection in animal (eq 6).

$$
A / D_{\text {ratio }}=\left(\frac{A_{\mathrm{em}}-A_{\text {autofluo }}}{D_{\text {em }}-D_{\text {autofluo }}}\right)
$$

In this simplified analysis, spectral cross-talks are not corrected. However, in order to obtain the percentage of intact FRET nanoparticles from the data, calibration curves were established for both in vivo and ex vivo experiments, using drops of mixtures of FRET-, DiI-, and DiD-loaded nanoparticles with different ratios, as detailed in the Supporting Information.

\section{RESULTS}

3.1. Design of FRET Lipid Nanoparticles. Figure 1A presents the structure of the nanoparticles used in this study.
LNCs and LNEs are both lipid-core nanoparticles with subtle differences. $^{21}$ They are produced by PIT (phase inversion temperature) or by sonication, respectively. LNC stability is ensured by its rigid shell, encapsulating a liquid lipid core of medium chain triglycerides ("capsule" structure). ${ }^{34}$ In contrast, LNE stability relies on the low water solubility of the solid core lipid mixture, whereas the nanoparticle shell is more mobile ("wax droplet" structure). ${ }^{37,38}$ Both systems are particularly suitable for efficient and stable hydrophobic molecule loading, and candidate nanovectors for in vivo drug delivery and imaging. ${ }^{22-26,31-33,39}$ Therefore, highly hydrophobic dialkylcarbocyanine dyes, $\mathrm{DiI}$ and $\mathrm{DiD}$, can be uploaded with efficiency $>95 \%$ in the particle lipid core, ${ }^{31,33}$ without modification of the particle size $(\approx 50 \mathrm{~nm}$ diameter in this study) and polydispersity (values listed in Tables S1 and S2 in the Supporting Information). DiI and DiD have originally been designed for cell membrane labeling, and they efficiently interact by FRET due to the strong spectral overlap between DiI emission and $\mathrm{DiD}$ absorption (Förster radius $R_{0}=5.2 \mathrm{~nm}$, see the Supporting Information).

Absorbance spectra and fluorescence spectra (recorded at donor excitation wavelength) of DiI/DiD-loaded LNCs with different donor (DiI)/acceptor (DiD) ratios are represented in 
A

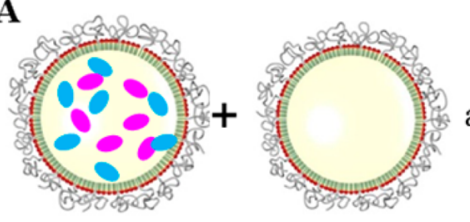

High FRET signal

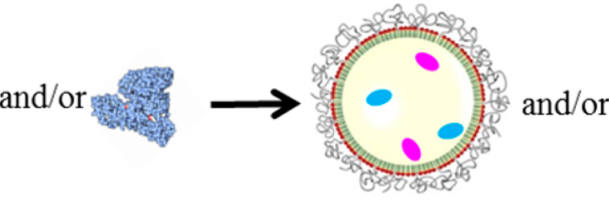

Low FRET signal

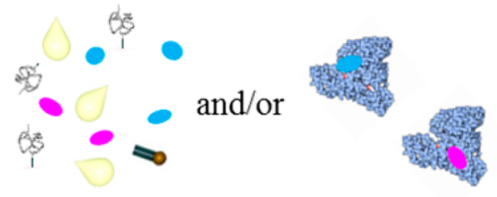

C

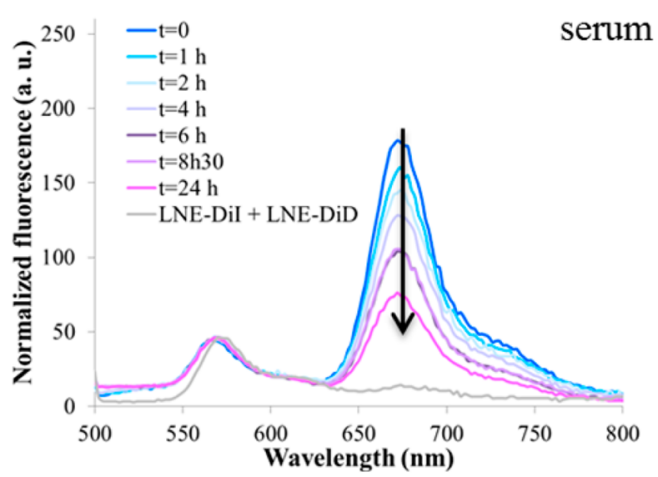

E

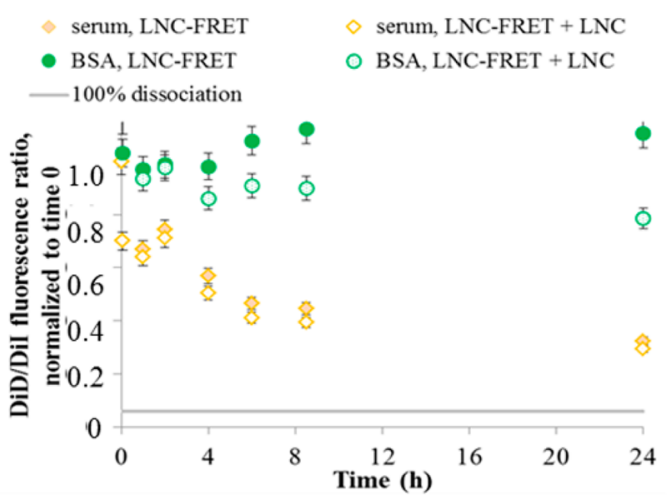

Figure 2. Stability of DiI/DiD FRET lipid nanoparticles upon lipid-mediated exchange and in biological media. (A) Schematic representation of processes that can lead to loss of FRET signal. (B, C) Time evolution of fluorescence spectra of DiI/DiD FRET LNEs when in contact with nonloaded LNEs in PBS (B) or serum (C) (excitation at $490 \mathrm{~nm}$, in the DiI absorption band; spectra are normalized to the maximum fluorescence intensity in the DiI band). (D, E) Normalized time evolution of DiD/DiI fluorescence for FRET LNEs (D) and FRET LNCs (E).

Figures $1 \mathrm{~B}$ and $1 \mathrm{C}$ respectively (lipid concentration of $1-5$ $\mathrm{mg} / \mathrm{mL}$ of lipids, local dye concentration in the particle core in the millimolar range). Similar results were obtained for DiI/ DiD-loaded LNEs (Figure S1 in the Supporting Information). Absorbance spectra of FRET nanoparticles were the sum of the DiI and DiD absorption bands, in the expected ratios according to the fluorophore quantities encapsulated in the nanoparticles (Figure 1B). In contrast, because of the presence of FRET from DiI to $\mathrm{DiD}$, an excitation at $510 \mathrm{~nm}$, corresponding to the DiI excitation wavelength, produced a decrease of the DiI and an increase of the $\mathrm{DiD}$ emission bands respectively, when the $\mathrm{DiD}$ core concentration was increased (Figure 1C). Experimental FRET transfer efficiency was calculated using eq 4, as detailed in the Experimental Section. This efficiency did not depend on the concentration of the donor (DiI), but increased with that of the acceptor $(\mathrm{DiD})$ and correlated with the theoretical values obtained for a model in which the two dyes are freely diffusing in an infinite solution of refractive index similar to that of soybean oil (further calculation details in the Experimental Section; Figure 1D).

We observed that nanoparticles loaded with $4 \mathrm{mM} \mathrm{DiD}$ presented a satisfying $80 \%$ FRET efficacy and that the curve reached a plateau, with a very modest augmentation of FRET when passing from 3 to $4 \mathrm{mM} \mathrm{DiD}$. Accordingly, it would have been necessary to reach very elevated $\mathrm{DiD}$ concentrations to further increase only marginally the FRET efficiency. As expected, FRET interactions between coencapsulated donors and acceptors were disrupted when the nanoparticles were destroyed. For instance, when in contact with organic media (DMSO), DiI fluorescence was no longer transferred to $\mathrm{DiD}$, and its emission was recovered (Figure 1E). The DiD/DiI fluorescence ratio can thus be considered as a reliable, simple, and quantitative indicator of nanoparticle integrity. The stability of LNCs and LNEs diluted in biological media, cell cultures, and mice was then assessed using the FRET imaging tool.

3.2. Encapsulation Stability of FRET Nanoparticles. When in contact with unloaded nanoparticles or plasma proteins, FRET nanoparticles can undergo lipid exchange or interactions that ultimately can lead to the loss of the FRET signal, because of dye/surfactant dynamic redistribution between nanoparticles, and/or particle dissociation, and/or dye leakage followed by their adsorption on plasma proteins, mediated by the interactions of these latters with the particle surface (Figure $2 \mathrm{~A}){ }^{40}$ Figure $2 \mathrm{~B}$ displays the time evolution of 

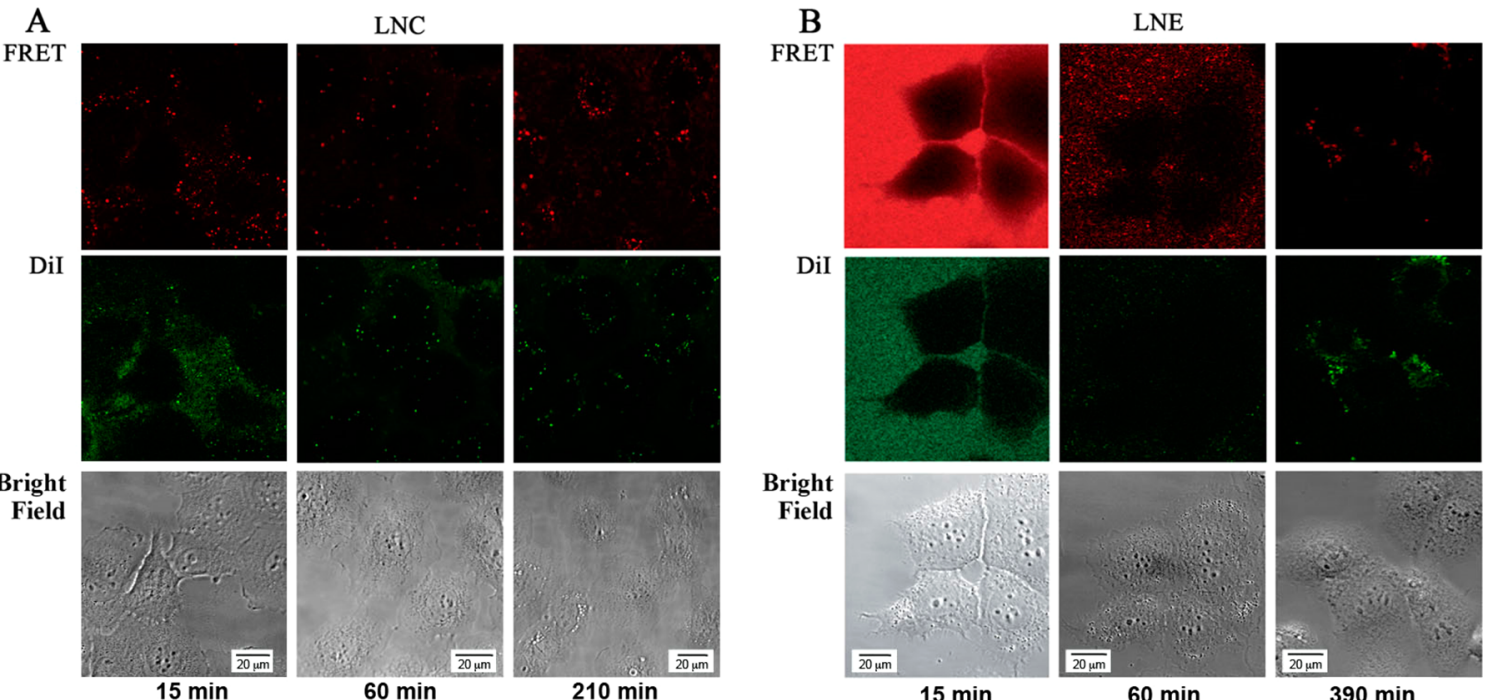

DiI
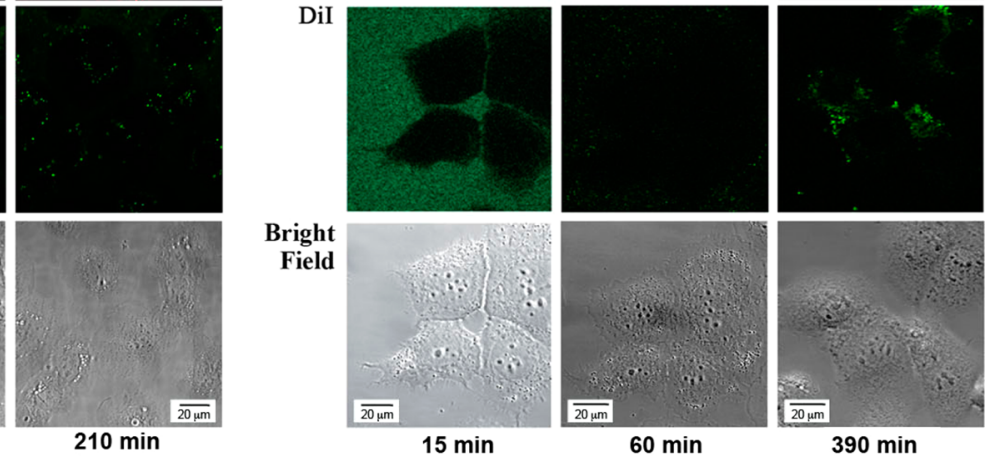

C

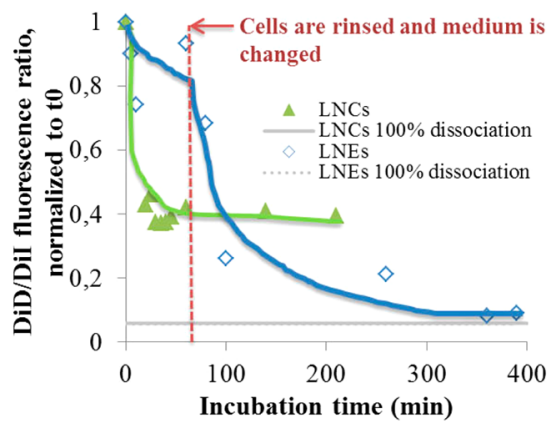

Figure 3. Kinetics of lipid nanoparticle internalization in HEK293 $\left(\beta_{3}\right)$ cells investigated by confocal microscopy. FRET LNCs (A) and FRET LNEs (B) were added to cells and analyzed at the indicated time after cells were rinsed. Upper panels represent the FRET signal, middle panels represent the DiI (donor) signal, and lower panels represent the bright field. All sets of images were acquired in the same conditions. Scale bar: $20 \mu \mathrm{m}$. (C) Quantification of the FRET signal of LNCs and LNEs coming from the cell cytoplasm during incubation with HEK293 $\left(\beta_{3}\right)$ cells.

fluorescence spectra (normalized to DiI maximum fluorescence) when DiI/DiD FRET nanoparticles were dispersed in PBS buffer in the presence of unloaded nanoparticles. Similar experiments were performed in PBS buffer, in the presence of bovine serum albumin (BSA $40 \mathrm{mg} / \mathrm{mL}$ ), or in bovine serum (Figure 2C), with the incubation of $0.2 \% \mathrm{w}: \mathrm{w}(2 \mathrm{mg} / \mathrm{mL})$ of FRET LNEs and LNCs, in the absence or in the presence of unloaded nanoparticles. The concentration of FRET nanoparticles $(2 \mathrm{mg} / \mathrm{mL}$ of lipids) used in the experiments corresponded to the concentration of nanoparticles after their blood injection in the in vivo experiments. The data were quantified and plotted as $\mathrm{DiD} / \mathrm{DiI}$ fluorescence ratio. Figures $2 \mathrm{D}$ and $2 \mathrm{E}$ present the results obtained respectively for LNEs and LNCs. Data obtained for PBS experiments are not shown on these graphs but were similar to those obtained for the BSA experiments. Overall, for both LNEs and LNCs, we observed a quite good stability of the nanoparticles in the presence of BSA (and in PBS) for at least $24 \mathrm{~h}$, as displayed by the stability of the FRET signal (Figure 2B,D,E). When unloaded lipid nanoparticles were added to the incubation medium, opening the possibility of FRET loss because of dynamic lipid exchange between nanoparticles, the slow decrease of the FRET signal was slightly accentuated $(-30 \%$ for the $\mathrm{DiD} / \mathrm{DiI}$ ratio in $24 \mathrm{~h}$ in the presence of unloaded nanoparticles versus $-10 \%$ for the $\mathrm{DiD} / \mathrm{DiI}$ ratio in $24 \mathrm{~h}$ in the absence of unloaded nanoparticles). This underlines that some dye exchange may have occurred in the presence of lipids, but in a rather limited way.
The presence of BSA in the PBS buffer did not alter the stability of the nanoparticles.

On the contrary, the presence of whole serum had more impact on the particle stability, which can be described in two steps. First, it was noted that in serum, even for very short times ( $<1$ min postincubation), the $\mathrm{DiD} / \mathrm{DiI}$ fluorescence ratio was decreased in comparison to PBS or BSA $(-25$ to $-30 \%$, Figure $2 \mathrm{C}, \mathrm{D}, \mathrm{E})$. Following this, the DiD/DiI FRET signal decreased continuously in a slow manner, to reach $30 \%$ of its initial value after $24 \mathrm{~h}$ incubation. Interestingly, it was noticed that the presence of nude nanoparticles in serum did not modify the kinetics of the loss of the FRET signal (for both LNEs and LNCs), indicating that this process was mainly governed by the presence of serum.

3.3. In Vitro Behavior of FRET Nanoparticles. In order to investigate the interactions of the lipid nanoparticles in contact with cells, DiI/DiD-loaded LNCs and LNEs were diluted in DMEM without FBS and without red phenol and incubated for $1 \mathrm{~h}$ at $37^{\circ} \mathrm{C}$ in the presence of HEK293 $\left(\beta_{3}\right)$ cells. Confocal fluorescence microscopy was performed using different filter sets: FRET (DiI (donor) excitation/(DiD) acceptor emission, pseudocolored in red in Figure 3A,B), DiI (DiI excitation and emission, pseudocolored in green in Figure $3 \mathrm{~A}, \mathrm{~B})$, and $\mathrm{DiD}$ ( $\mathrm{DiD}$ excitation and emission). As seen by the images acquired in the FRET and DiI channels, LNCs were internalized into cells as rapidly as $1 \mathrm{~h}$ after incubation (FRET and DiI signals, Figure 3A), whereas LNEs were mostly 
observed on the cell membranes (Figure 3B). After $1 \mathrm{~h}$ incubation, the medium was removed and replaced by fresh medium, to better quantify the FRET signal issued after the cell internalization of the particles. For longer incubation times, FRET signal was lower for LNEs than for LNCs, whereas DiI fluorescence, which could be observed in the cytoplasm, was stronger for LNEs than for LNCs, indicating degradation of the LNEs.

The FRET signal coming from the cell cytoplasm was quantified by the $\mathrm{DiD} / \mathrm{DiI}$ fluorescence ratio (each one recorded in its respective channel) in order to evaluate the integrity of the particles and their possible dissociation during the internalization process. Figure $3 \mathrm{C}$ demonstrates two different behaviors for LNCs and LNEs. For LNCs, whose internalization process started at earlier incubation times than for LNEs (Figure 3A,B), the FRET signal decreased rapidly in the first minutes of incubation, and then a plateau was reached and only partial FRET loss was observed. More importantly, after the cells were rinsed and incubated in fresh culture medium after $1 \mathrm{~h}$ incubation, no more FRET signal decrease was observed. This indicated that the nanoparticles that were internalized into the cells remained intact up to $3 \mathrm{~h}$ after incubation. In contrast, fewer LNEs were internalized in cells for early incubation times (Figure 3B), therefore the FRET signal was initially high originating from the culture medium and cell membrane. When cells were rinsed and incubated in a fresh medium, the FRET signal only originated from the cell interior, and rapid decrease of the FRET signal was observed. This indicated a fast dissociation of LNEs after their internalization, leading to complete particle dissociation $6 \mathrm{~h}$ after the experiment started.

3.4. In Vivo Behavior of FRET Nanoparticles. The in vivo fate of the FRET LNCs was then assessed following their intravenous injection in nude mice bearing subcutaneous TS/ A-pc tumor. This tumor model was chosen for its high EPR effect. ${ }^{21}$ The simple ratio of acceptor over donor fluorescence $\left(A / D_{\text {ratio }}\right)$, each acquired in their respective channels and corrected from autofluorescence background, was used to quantitatively estimate FRET in vivo (eq 6, Experimental Section). A calibration curve to link the experimentally measured $A / D_{\text {ratio }}$ with the \% of intact FRET nanoparticles contributing to the fluorescence signal was established. This curve was obtained by measuring the $\mathrm{DiI}$ and $\mathrm{DiD}$ signals from solutions containing various concentrations of FRET LNCs, DiI LNCs, and DiD LNCs, as detailed in the Supporting Information (Figure S4). Two specific regions of interest (ROI) were drawn around the tumor and liver in order to measure $A / D_{\text {ratio }}, 1,5$, or $24 \mathrm{~h}$ after intravenous injection of FRET LNCs in the animals (Figure S3 in Supporting Information), with quantification reported in Table 1. The intensity of FRET decreased with time, more rapidly in the liver than in the tumor. No FRET was detectable in the liver $24 \mathrm{~h}$ after injection, suggesting that the degradation of the lipid nanocapsules was complete in this organ, while intact LNCs could still be present in the tumor. Liver is an aggressive environment that degrades LNC more efficiently than tumors, but is also a very absorbing and thick tissue that will generate a stronger absorption of photons emitted by $\mathrm{DiI}$ than by $\mathrm{DiD}$. These two phenomena can explain the artificial negative value obtained at $24 \mathrm{~h}$ in the liver, at a moment when all FRET nanoparticles would be destroyed (Table 1 ).

To confirm these results, thin tumor sections $(7 \mu \mathrm{m})$ were observed ex vivo under confocal microscopy, and FRET was
Table 1. FRET Ratio Obtained in Vivo at 1, 5, and $24 \mathrm{~h}$ after Injection of FRET LNCs ${ }^{a}$

$\begin{array}{lccc} & \text { time after injection, } \mathrm{h} & A / D_{\text {ratio }} & \text { theor } \% \text { of intact LNCs } \\ \text { liver } & 1 & 31.3 \pm 4.7 & 46.7 \pm 12.7 \\ & 5 & 19.4 \pm 2.3 & 14.3 \pm 6.3 \\ \text { tumor } & 24 & 11.1 \pm 0.3 & <0^{b} \\ & 1 & 30.7 \pm 3.4 & 45.1 \pm 9.3 \\ & 5 & 21.6 \pm 1.9 & 20.4 \pm 5.2 \\ & 24 & 17.2 \pm 1.5 & 8.3 \pm 4.1\end{array}$

${ }^{a}$ Values represent mean fluorescence of regions of interest measured on whole-body images, and indicated error bars correspond to standard deviation of the fluorescence signal in different animals $(n \geq$ 3 /group). ${ }^{b}$ A negative value is obtained in the liver at $24 \mathrm{~h}$ when using the calibration curve $(-8.1 \pm 0.9)$, probably because of the stronger absorption of photons emitted by DiI than by DiD in this highly absorbing and thick tissue.

quantified using the $\mathrm{DiD} / \mathrm{DiI}$ fluorescence ratio. The values obtained were converted into the $\%$ of intact FRET nanoparticles using a calibration curve, as was done for in vivo experiments (Figure 4). Similarly to what was observed on

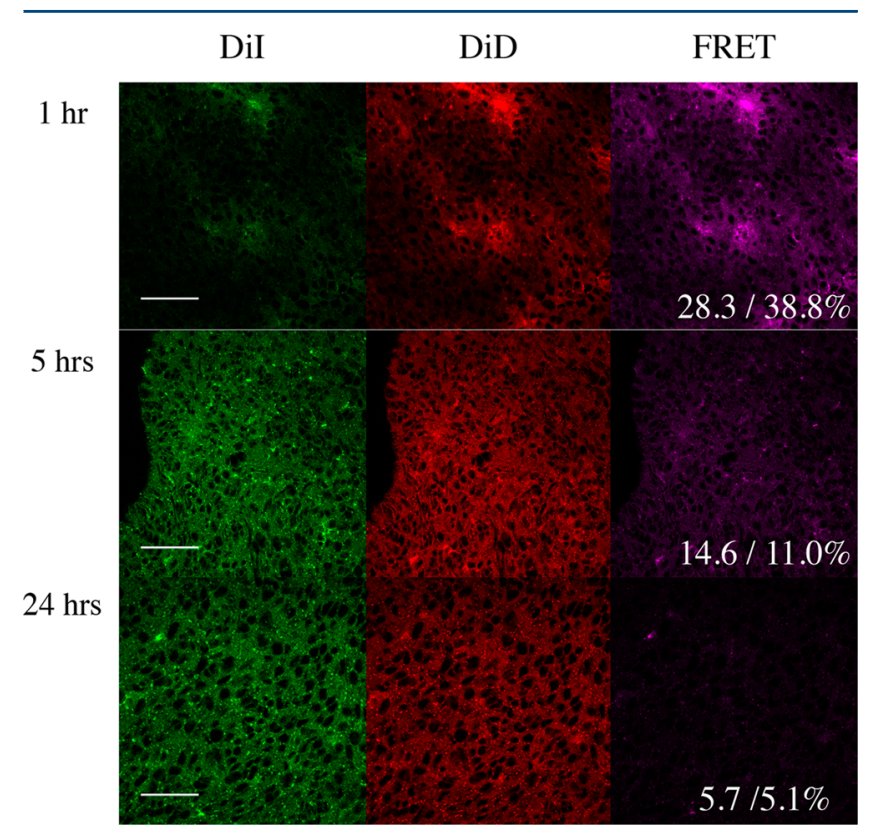

Figure 4. Confocal microscopy images of tumor sections, 1, 5, and 24 $\mathrm{h}$ after the injection of FRET LNCs. After the optical imaging experiment, the tumor sections $(7 \mu \mathrm{m})$ were analyzed under confocal microscope. The FRET between the donor (DiI, ex 543 nm, em 550$600 \mathrm{~nm}$ ) and the acceptor (DiD, ex $633 \mathrm{~nm}$, em 670-748 nm) was observed at $670-748 \mathrm{~nm}$. The \% of FRET calibration curve was established using drop solutions of monodye LNC. The DiD/DiI fluorescence ratios, as well as the theoretical percentage of LNCs containing the initial payload, were indicated in the right lower corner. Scale bar: $50 \mu \mathrm{m}$.

whole-body images (Table 1), ex vivo measurement of the FRET signal on tumor sections was also decreasing over time. About $39 \%$ of the LNCs were intact $1 \mathrm{~h}$ after injection, $\sim 11 \%$ after $5 \mathrm{~h}$, and $6 \%$ after $24 \mathrm{~h}$.

\section{DISCUSSION}

FRET is a well-acknowledged method to study a variety of biological processes, such as changes in protein conformations, biomolecular interactions, lipid membrane, and protein 
dynamics. ${ }^{18,19}$ Recently, FRET was used to study the exchange of dye-functionalized surfactants and phospholipids in micelles, ${ }^{41-43}$ liposomes, ${ }^{40}$ and HDL-like nanoparticle assemblies (HDL: high density lipoproteins), ${ }^{44}$ in aqueous media or in cell cultures. ${ }^{40,44}$ The encapsulation of FRET fluorophore pairs as model drugs in different polymer-based nanoparticles, ${ }^{45,46}$ micelles, ${ }^{41-43,47}$ and lipid nanodroplets ${ }^{48}$ was also used to investigate the stability of the carriers in aqueous media and blood, their internalization in cancer cells, and their content release mechanism. ${ }^{42,43,45-47}$ However, there are still very few publications reporting the use of FRET for in vivo studies. ${ }^{41,49-52}$ PLGA-PEG (PLGA, poly lactic-co-glycolic acid; PEG, poly(ethylene glycol) $)^{49}$ and PS-PEG (PS, polystyrene) $)^{52}$ polymeric nanoparticles encapsulating the $\mathrm{DiD} / \mathrm{DiR}$ nearinfrared FRET pair have been previously designed in order to study dye release kinetics ${ }^{52}$ or to achieve large Stokes shift contrast agents for in vivo imaging. ${ }^{49}$ Higher fluorescence signal to background ratio was reported with the new imaging probes, and demonstrated in phantoms. ${ }^{49}$ In a pioneering report, the dissociation of PLA-PEG micelles (PLA, poly(lactic acid)) in blood circulation after their tail intravenous injection in mouse was studied by FRET imaging in ear lobe vessels. ${ }^{41}$ Dissociation of the FRET pair, and hence of the micelles, was observed as early as $15 \mathrm{~min}$ after injection, and attributed to strong nanoparticle interactions with $\alpha$ - and $\beta$-globulins. ${ }^{41}$ In a very recent study, the dissociation and tumor accumulation of FRET quantum dot core self-assembled lipid nanoparticles was studied in HCT-116 xenograft-bearing mice. ${ }^{50}$ The rapid sequestration of the quantum dot core in tumor, lymph nodes, and macrophage-homing organs was observed, whereas the $\mathrm{Cy} 7$ coated lipids were cleared in the circulatory system and through kidneys. ${ }^{50}$ In this context, we explored the potentialities of the FRET tool to study the stability of two types of lipid nanoparticles in serum, during cell uptake and internalization, and after intravenous injection in tumor-bearing mice.

4.1. FRET Methodology. In microscopy experiments, "crude" FRET signal is usually converted to net FRET value, by eliminating cross-talks of donor and acceptor fluorophores in the FRET channel. ${ }^{49,53}$ Net FRET is given by eq 7 :

$$
\text { netFRET }=\text { FRET }_{\mathrm{em}}-a D_{\mathrm{em}}-b A_{\mathrm{em}}
$$

in which $D_{\mathrm{em}}$ is the donor (DiI) excitation/emission, FRET $_{\mathrm{em}}$ is the donor excitation/acceptor emission, and $A_{\mathrm{em}}$ is the acceptor (DiD) excitation/emission. FRET ratios are then calculated using eq $8:^{49,53}$

$$
\text { FRET }_{\text {ratio }}=\frac{\text { netFRET }}{D_{\mathrm{em}}}
$$

However, when we used the above FRET calculation method on images acquired in in vivo experiments, irreproducible and negative net FRET values were obtained. Direct in vivo FRET imaging is indeed challenging since optical properties in diffuse media such as tissues are highly wavelength-dependent. First, when the wavelength of excitation is set at 535 or $640 \mathrm{~nm}$, photons do not travel as efficiently in tissues. ${ }^{54}$ The donor (DiI) is less excited at $535 \mathrm{~nm}$ than the acceptor (DiD) at 640 $\mathrm{nm}$ for a similar depth location $(2 \mathrm{~mm}$ beneath skin for instance). The acceptor emission $A_{\mathrm{em}}$ (DiD) values are thus more elevated than the FRET emission $\left(\right.$ FRET $\left._{\mathrm{em}}\right)$, and negative net FRET values are obtained when using eq 7 . Second, autofluorescence of the tissues is more important at $535 \mathrm{~nm}$ than at $640 \mathrm{~nm}$. In addition, autofluorescence varies between the different organs, inducing important and nonreproducible bleed-through of the donor signal into the acceptor channel. On the contrary, it was checked that the quantification of the \% of intact FRET nanoparticles in tumor sections measured by confocal microscopy ex vivo gave consistent results when calibrated using the $\mathrm{DiD} / \mathrm{DiI}$ fluorescence ratio as used in this study (eq 6), or the $\mathrm{FRET}_{\text {ratio }}$ as classically used in microscopy studies (eq 2) (Table S3 in Supporting Information). For ex vivo experiments, as for classical microscopy experiments, the tissue slices were sufficiently thin $(7 \mu \mathrm{m})$ to neglect issues due to variation of light penetration depth with wavelength. Therefore, the use of the $\mathrm{DiD} / \mathrm{DiI}$ fluorescence ratio for FRET quantification was used all along this study, since this quantification method can be used for physicochemical characterizations, as well as cell and mouse experiments.

4.2. Particle Stability in Serum. We observed that both lipid nanoparticles (LNCs and LNEs) were quite stable in PBS buffer when incubated alone (less than $10 \%$ decrease for the $\mathrm{DiD} / \mathrm{DiI}$ signal in $24 \mathrm{~h}$ ), despite the conditions of the test: 37 ${ }^{\circ} \mathrm{C}$ incubation; important dilution $(2 \mathrm{mg} / \mathrm{mL}$ of lipids $)$. The presence of unloaded nanoparticles, opening the way to supplementary dye/surfactant exchanges between nanoparticles, increased the decay of the FRET signal $(-30 \%$ in PBS in $24 \mathrm{~h}$ in the presence of nude nanoparticles). When stored at $4{ }^{\circ} \mathrm{C}$ at $100 \mathrm{mg} / \mathrm{mL}$ of lipids in PBS buffer, the FRET signal of LNEs and LNCs dispersions was very stable ( $>6$ months) (Figure S2 in the Supporting Information). Higher temperature is known to favor surfactant exchange dynamics in selfassembled nanoparticles. ${ }^{44}$ Important particle dilution can also destabilize the particle shell if the surfactants that enter its composition are in equilibrium with free surfactants in solution, like for micelle assemblies. The critical micelle concentration of the PEG surfactants entering the composition of the lipid nanoparticles of the present study has been reported to be 75$300 \mu \mathrm{M}$ for Solutol HS15 and 4-7 $\mu \mathrm{M}$ for Mirj S40, ${ }^{55}$ respectively used for LNCs and LNEs. These low values ensure the good stability of the nanoparticles, even in diluted conditions.

Interestingly, no significant difference was observed in the kinetics of decrease of the FRET signal when nanoparticles were incubated in PBS buffer or in PBS buffer complemented with albumin $(40 \mathrm{mg} / \mathrm{mL} \mathrm{BSA})$, the most abundant plasma protein. It was previously demonstrated that both LNCs and LNEs display very low complement activation, ${ }^{21}$ and this was accounted for by the PEG coating of the nanoparticles, known to prevent protein adsorption. On the contrary, whole serum had more impact on FRET and hence particle stability and/or dye leakage, and in this case the kinetics of the loss of the FRET signal was not affected by the presence of unloaded nanoparticles. We can assume that serum proteins of a different nature than albumin are implicated in the particle interactions leading to the moderate loss of FRET signal. $\alpha$ - and $\beta$ globulins, but not $\gamma$-globulin (nor red blood cells and albumin), were reported to be the major serum proteins responsible for dissociation of FRET PLA-PEG micelles. ${ }^{41}$ However, another study, also performed on PLA-PEG micelles, concluded that global increase in serum protein concentration increased micelle destabilization, but without identifying any of the major serum proteins in particular to be responsible for the process. ${ }^{43}$ Apolipoproteins have been shown to be the main plasma proteins to interact with PEGylated solid lipid nanoparticles after their intravenous injection, in a PEG length 
dependent pattern. ${ }^{56,57}$ We recently studied the biodistribution of radiolabeled LNEs and evidenced common patterns with that of natural blood-circulating very low density lipoproteins (VLDL). These patterns included relatively quick plasma clearance $(\approx 30 \mathrm{~min})$, liver metabolization, and specific affinity for steroid hormone rich areas and/or lipoprotein receptors. ${ }^{58}$ VLDLs, in addition to their lipid core composition (50\% triglycerides, 50\% cholesterol and cholesterol esters), display sizes similar to LNCs and LNEs (30-80 nm diameter) and a high shell content in phospholipids, ${ }^{59}$ and different apolipoproteins (mainly ApoB-100, ApoC-I, ApoCI-I, ApoC-III, and Apo-E) stabilize their surface. It was also recently demonstrated that lipoprotein-lipoprotein interactions lead to very fast lipid exchanges in high density lipoproteins (HDL), as measured by FRET using quantum dot core self-assembled lipid nanoparticles as HDL mimics. ${ }^{44}$ When coated with Apo-AI prior to incubation, these nanoparticles were more stable. ${ }^{44}$ Taken together, all these elements could indicate that apolipoproteins could be the main serum proteins implicated in the LNE and LNC interactions with serum, leading to their progressive destabilization and/or dye leakage.

Interestingly, serum destabilization kinetics presented two phases: a very quick destabilization, which was observed as soon as the nanoparticles were in contact with serum $(<1 \mathrm{~min})$ and which was responsible for $\approx 20 \%$ of FRET signal loss, and a slower phase, which was responsible for $\approx 50 \%$ FRET decrease in $24 \mathrm{~h}$. The protein corona pattern on nanoparticles when incubated in plasma is known to be time-dependent, with the most abundant proteins adsorbing very rapidly (less than a few seconds in nondiluted plasma), and then reorganization occurs to achieve in fine adsorption of proteins presenting the highest affinity for the particle surface (Vroman effect). ${ }^{60}$ Such a timedependent pattern could account for the observed two-phase kinetics in the FRET signal loss of LNCs and LNEs when incubated in serum. However, the overall FRET decrease observed for LNEs and LNCs (70\% in $24 \mathrm{~h}$ ) was quite limited in serum when the nanoparticle dispersions were diluted. For comparison, lipid droplets similar to the ones used in this study displayed FRET loss of $50 \%$ in about $6 \mathrm{~h},{ }^{48}$ whereas polymer nanogels needed to be cross-linked to retain FRET dye pair for hours when incubated in serum. ${ }^{45}$ Self-assembled nanosystems, such as PLA-PEG micelles ${ }^{41}$ or quantum dot core lipid nanoparticles, ${ }^{50}$ presented very short lifetimes when incubated in serum (tens of minutes).

4.3. Particle Interaction with Cells. The kinetics of internalization in the HEK293 $\left(\beta_{3}\right)$ cells of the two types of lipid nanoparticles (LNEs and LNCs) was quite slow, in agreement with previously reported results, ${ }^{21}$ and reflected their expected stealth behavior resulting from their efficient surface shielding with PEG polymers. However, clear differences were observed in the internalization pattern of the two particles despite their apparent and misleading similar chemical composition. LNCs were internalized rapidly, and were quite stable within the cell, whereas LNEs entered the cell with slower kinetics and released their content rapidly after internalization. In reality, LNC and LNE shells contain different amounts and types of PEG surfactants. LNE shell includes long PEG polymers $(2 \mathrm{kDa})$ while LNCs contain smaller PEG chains $(750 \mathrm{Da})$ but at a higher density, providing a "brush-like" conformation and augmented rigidity and crystalline properties. ${ }^{61}$ The long PEG chains and their mushroom conformation on LNEs could prevent their rapid cell uptake by limiting particle interactions with cell membranes, whereas better interactions could occur between LNCs and cells. It has been previously proposed that the fast dye release content (in $\approx 40 \mathrm{~min}$ ) of FRET PLA-PEG micelles occurring during incubation with $\mathrm{KB}$ cells was due to the important PEG surface density that could bridge the micelle core and the lipid membrane for transfer of hydrophobic molecules. ${ }^{42}$ A similar process could occur with LNCs, for which "brush" PEG high density exists on the particle surface. That could account for the rapid dissociation of the particles observed during the first hour of incubation (Figure 3C, before cells are rinsed, during particle uptake). However, only about $60 \%$ of LNCs were dissociated upon internalization, and once they entered intact in the cell compartment, they remained quite stable, possibly because of their quite rigid crystalline shell. A macrophage internalization study performed with FRET quantum dot core HDL mimics evidenced that FRET loss occurred both at the cell membrane and in the cytoplasm, indicating that a proportion of intact nanoparticles could enter the cells in $\approx 20$ min. ${ }^{44}$ LNEs were internalized during the first hour of incubation in a lesser quantity than for LNCs, and with reduced FRET loss, suggesting less dissociation and hence probably less exchange with membrane lipids during internalization. However, once internalized, they completely dissociated in a few hours, a little slower than what was observed for HDL-like particles, for which FRET signal was completely lost $1 \mathrm{~h}$ after macrophage incubation. ${ }^{44}$

4.4. In Vivo Particle Behavior. Similar to cell studies, FRET can be used in vivo, and was used to assess the fate of LNCs after their intravenous injection in tumor-bearing mice. A long lasting presence of intact, FRET positive LNCs was found in the tumor at the macroscopic level, since $20.4 \%$ of the signal still came from FRET $5 \mathrm{~h}$ after intravenous injection, a proportion that was very close to the $14.6 \%$ evaluated on tumor sections. This is in agreement with the in vitro experiments which demonstrated that, despite an immediate FRET loss in a serum and/or cell containing medium, but not in the presence of BSA, the LNCs that remained intact after a few minutes were very resistant to degradation and could release their content slowly and regularly over time. $6-8 \%$ of them were still intact in the tumor $24 \mathrm{~h}$ after injection, although they did not resist the aggressive liver environment. Chen et al. injected DiI/DiDloaded PLA-PEG micelles intravenously and studied their dissociation by confocal microscopy in the capillaries of the ear lobe of mice. ${ }^{41}$ This necessitated placing the ear under a coverslip. A quick and nearly complete release of core-loaded dyes from circulating micelles was observed in about $15 \mathrm{~min}^{41}$ Wagh et al. designed PLGA-PEG polymeric nanoparticles encapsulating the $\mathrm{DiD} / \mathrm{DiR}$ near-infrared FRET pair ${ }^{49}$ and studied their integrity ex vivo on the mouse organs, and in vivo using a capillary inserted in the mice. No quantitative data were drawn from the study, but FRET signal was observed ex vivo 24 $\mathrm{h}$ after injection in liver and spleen, suggesting that part of the nanoparticles were still intact at that time in these organs. ${ }^{49}$ The authors also noted an important cross-talk and signal background present in "crude" FRET images in agreement with our current results. This could be particularly important in the liver due to its specialized activity on the metabolism of lipids and its important interference with optical parameters. To overcome these limitations, near-infrared dye FRET pairs should be used. However, we here demonstrated that the FRET tool can provide very important information concerning the cell internalization pathways of drug nanocarriers, as well as the kinetics and localization of their payload release. These processes will be further explored in vivo in the future. ${ }^{62}$ 


\section{CONCLUSION}

A noninvasive FRET-based methodology to achieve insight into lipid nanoparticle stability and fate, both in vitro and in vivo, was presented. This technique can provide information on both the distribution of dyes as drug models and the integrity of their nanocarrier, followed by their FRET interaction. In particular, we demonstrated that, once past the immediate disintegration of more than half of the LNCs in the presence of serum or cells, the remaining particles were stable for a surprisingly long period of time in particular in the tumor microenvironment. Since this was determined microscopically as well as macroscopically, we can assume that the method is valid and reliable. Despite similar structures and similar serum stability, LNCs and LNEs displayed different interactions with cells. It underlines that fine structure and organization of the particle surface are key elements governing the in vitro and in vivo behavior of nanocarriers. These aspects will be further investigated using near-infrared dye FRET pair, allowing deeper tissue imaging and more accurate in vivo quantification. ${ }^{62}$

\section{ASSOCIATED CONTENT}

\section{S Supporting Information}

Physicochemical characterizations of FRET LNCs and LNEs; complement for the calculation of FRET efficiency; in vivo images of mice; calibration curve linking the measured $(A$ / $\left.D_{\text {ratio }}\right)$ with the $\%$ of intact FRET nanoparticles; comparison of $\%$ of FRET nanoparticles quantitated using DiI/DiD fluorescence ratio (eq 6) versus the $\mathrm{FRET}_{\text {ratio }}$ (eq 8). This material is available free of charge via the Internet at http:// pubs.acs.org.

\section{AUTHOR INFORMATION}

\section{Corresponding Authors}

*(I.T.) E-mail: isabelle.texier-nogues@cea.fr. Tel: (+33) 438 784 670. Fax: (+33) 438785787.

*(J.-L.C.) E-mail: Jean-Luc.Coll@ujf-grenoble.fr. Tel: $(+33)$ 476549 553. Fax: $(+33) 476549413$.

\section{Author Contributions}

${ }^{\perp}$ J.G. and L.S. contributed equally.

\section{Notes}

The authors declare no competing financial interest.

\section{ACKNOWLEDGMENTS}

We thank the Commissariat à l'Energie Atomique et aux Energies Alternatives (CEA) and the French National Research Agency (ANR, CALIF project $\mathrm{n}^{\circ}$ ANR-08-NANO-006) for their financial support. LETI/DTBS is part of the Arcane LabEx program, funded by the French National Research Agency (ARCANE project $\mathrm{n}^{\circ}$ ANR-12-LABX-003).

\section{ABBREVIATIONS USED}

FRET, Förster resonance energy transfer; LNC, lipid nanocapsules; LNE, lipid nanoemulsions; TEM, transmission electron microscopy; AFM, atomic force microscopy; FTIR, Fourier transform infrared spectroscopy; NMR, nuclear magnetic resonance; EPR, enhanced permeability and retention; PIT, phase inversion temperature

\section{REFERENCES}

(1) Sahoo, S. K.; Parveen, S.; Panda, J. J. The present and future of nanotechnology in human health care. Nanomedicine 2007, 3, 20-31.
(2) Wagner, V.; Dullaart, A.; Bock, A.-K.; Zweck, A. The emerging nanomedicine landscape. Nat. Biotechnol. 2006, 24 (10), 1211-1217.

(3) Wang, A. Z.; Langer, R.; Farokhzad, O. C. Nanoparticle delivery of cancer drugs. Annu. Rev. Med. 2012, 63, 185-198.

(4) Licha, K.; Olbrich, C. Optical imaging in drug discovery and diagnostic applications. Adv. Drug Delivery Rev. 2005, 57, 1087-1108.

(5) Sancey, L.; Dufort, S.; Josserand, V.; JKeramidas, M.; Righini, C.; Rome, C.; Faure, A. C.; Foillard, S.; Roux, S.; Boturyn, D.; Tillement, O.; Koenig, A.; Boutet, J.; Rizo, P.; Dumy, P.; Coll, J. L. Drug development in oncology assisted by noninvasive optical imaging. Int. J. Pharm. 2009, 379, 309-316.

(6) Sevick-Muraca, E. M.; Rasmussen, J. C. Molecular imaging with optics: primer and case for near-infrared fluorescence techniques in personalized medicine. J. Biomed. Opt. 2008, 13 (4), 041303.

(7) Portnoy, E.; Lecht, S.; Lazarovici, P.; Danino, D.; Magdassi, S. Cetuximab-labeled liposomes containing near-infrared probe for in vivo imaging. Nanomedicine 2011, 7 (4), 480-488.

(8) Cormode, D. P.; Jarzyna, P. A.; Mulder, W.; Fayad, Z. A. Modified natural nanoparticles as contrast agents for medical imaging. Adv. Drug Delivery Rev. 2010, 62, 329-338.

(9) Zhang, Z.; Chen, J.; Ding, L.; Jin, H.; Lovell, J. F.; Corbin, I.; Cao, W.; Lo, P.-C.; Yang, M.; Tsao, M.-S.; Luo, Q.; Zheng, G. HDLmimicking peptide-lipid nanoparticles with improved tumor targeting. Small 2010, 6 (3), 430-437.

(10) Schädlich, A.; Rose, C.; Kuntsche, J.; Caysa, H.; Mueller, T.; Göpferich, A.; Mäder, K. How stealthy are PEG-PLA nanoparticles? An NIR in vivo study combined with detailed size measurements. Pharm. Res. 2011, 28, 1995-2007.

(11) Longmire, M. R.; Ogawa, M.; Choyke, P. L.; Kobayashi, H. Biologically optimized nanosized molecules and particles: more than just size. Bioconjugate Chem. 2011, 22 (6), 993-1000.

(12) Burns, A.; Vider, J.; Ow, H.; Herz, E.; Penate-Medina, O.; Baumgart, M.; Larson, S. M.; Wiesner, U.; Bradbury, M. Fluorescent silica nanoparticles with efficient urinary excretion for nanomedicine. Nano Lett. 2009, 9 (1), 442-448.

(13) Kumar, R.; Roy, I.; Ohulchanskyy, T.; Vathy, L. A.; Bergey, E.; Sajjad, M.; Prasad, P. In vivo biodistribution and clearance studies unsing multimodal organically modified silica nanoparticles. ACS Nano 2010, 4 (2), 699-708.

(14) Liong, M.; Lu, J.; Kovochich, M.; Xia, T.; Ruehm, S. G.; Nel, A. E.; Tamanoi, F.; Zink, J. I. Multifunctional inorganic nanoparticles for imaging, targeting, and drug delivery. ACS Nano 2008, 2 (5), 889896.

(15) Barth, B. M.; Altinoglu, E. I.; Shanmugavelandy, S. S.; Kaiser, J. M.; D, C.-G.; DiVittore, N. A.; McGovern, C.; Goff, T. M.; Keasey, N. R.; Adair, J. H.; Loughran, T. P.; Claxton, D. F.; Kester, M. Targeted indocyanine-green-loaded calcium phosphosilicate nanoparticles for in vivo photodynamic therapy of leukemia. ACS Nano 2011, 5 (7), 5325-5337.

(16) Epple, M.; Ganesan, K.; Heumann, R.; Klesing, J.; Kovtun, A.; Neumann, S.; Sokolova, V. Application of calcium phosphate nanoparticles in biomedicine. J. Mater. Chem. 2010, 20, 18-23.

(17) Faure, A.-C.; Dufort, S.; Josserand, V.; Perriat, P.; Coll, J. L.; Roux, S.; Tillement, O. Control of the in vivo biodistribution of hybrid nanoparticles with different poly(ethyleneglycol) coatings. Small 2009, 5 (22), 2565-2575.

(18) Fruhwirth, G. O.; Fernandes, L. P.; Weitsman, G.; Patel, G.; Kelleher, M.; Lawler, K.; Brock, A.; Poland, S. P.; Matthews, D. R.; Kéri, G.; Barber, P. R.; Vojnovic, B.; Ameer-Beg, S. M.; Coolen, A. C. C.; Fraternali, F.; Ng, T. How Förster resonance energy transfer imaging improves the understanding of protein interaction networks in cancer biology. ChemPhysChem 2011, 12 (3), 442-461.

(19) Sahoo, H. Förster resonnance energy transfer - a spectroscopic nanoruler: principle and applications. J. Photochem. Photobiol., C 2011, $12,20-30$.

(20) Lakowicz, J. R. Principles of Fluorescence Spectroscopy, 2nd ed.; Kluwer Academics/Plenum Publishers: New York, 1999.

(21) Hirsjärvi, S.; Dufort, S.; Gravier, J.; Texier, I.; Yan, Q.; Bibette, J.; Sancey, L.; Josserand, V.; Passirani, C.; Benoit, J.-P.; Coll, J.-L. 
Influence of size, surface coating and fine chemical composition on the in vitro reactivity and in vivo biodistribution of lipid nanocapsules versus lipid nanoemulsions in cancer models. Nanomedicine 2013, 9 (3), 375-387.

(22) Peltier, S.; Oger, J. M.; Lagarce, F.; Couet, W.; Benoit, J. P. Enhanced oral paclitaxel bioavailability after administration of paclitaxel-loaded lipid nanocapsules. Pharm. Res. 2006, 23 (6), $1243-1250$

(23) Lacoeuille, F.; Hindre, F.; Moal, F.; Roux, J.; Passirani, C.; Couturier, O.; Cales, P.; Le Jeune, J. J.; Lamprecht, A.; Benoit, J. P. In vivo evaluation of lipid nanocapsules as a promising colloidal carrier for paclitaxel. Int. J. Pharm. 2007, 344 (1-2), 143-149.

(24) Garcion, E.; Lamprecht, A.; Heurtault, B.; Paillard, A.; AubertPouessel, A.; Denizot, B.; Menei, P.; Benoit, J. P. A new generation of anticancer, drug-loaded, colloidal vectors reverses multidrug resistance in glioma and reduces tumor progression in rats. Mol. Cancer Ther. 2006, 5 (7), 1710-1722.

(25) Cirpanli, Y.; Allard, E.; Passirani, C.; Bilensoy, E.; Lemaire, L.; Calis, S.; Benoit, J. P. Antitumoral activity of camptothecin-loaded nanoparticles in 9L rat glioma model. Int. J. Pharm. 2011, 403 (1-2), 201-206.

(26) Lamprecht, A.; Saumet, J. L.; Roux, J.; Benoit, J. P. Lipid nanocarriers as drug delivery system for ibuprofen in pain treatment. Int. J. Pharm. 2004, 278 (2), 407-414.

(27) Morille, M.; Montier, T.; Legras, P.; Carmoy, N.; Brodin, P.; Pitard, B.; Benoit, J. P.; Passirani, C. Long-circulating DNA lipid nanocapsules as new vector for passive tumor targeting. Biomaterials 2010, 31 (2), 321-329.

(28) Morille, M.; Passirani, C.; Dufort, S.; Bastiat, G.; Pitard, B.; Coll, J. L.; Benoit, J. P. Tumor transfection after systemic injection of DNA lipid nanocapsules. Biomaterials 2011, 32 (9), 2327-33.

(29) Vanpouille-Box, C.; Lacoeuille, F.; Belloche, C.; Lepareur, N.; Lemaire, L.; LeJeune, J. J.; Benoit, J. P.; Menei, P.; Couturier, O. F.; Garcion, E.; Hindre, F. Tumor eradication in rat glioma and bypass of immunosuppressive barriers using internal radiation with (188)Relipid nanocapsules. Biomaterials 2011, 32 (28), 6781-6790.

(30) Allard, E.; Hindre, F.; Passirani, C.; Lemaire, L.; Lepareur, N.; Noiret, N.; Menei, P.; Benoit, J. P. 188Re-loaded lipid nanocapsules as a promising radiopharmaceutical carrier for internal radiotherapy of malignant gliomas. Eur. J. Nucl. Med. Mol. Imaging 2008, 35 (10), $1838-1846$.

(31) Goutayer, M.; Dufort, S.; Josserand, V.; Royere, A.; Heinrich, E.; Vinet, F.; Bibette, J.; Coll, J. L.; Texier, I. Tumor targeting of functionalized lipid nanoparticles: assessment by in vivo fluorescence imaging. Eur. J. Pharm. Biopharm. 2010, 75 (2), 137-147.

(32) Texier, I.; Goutayer, M.; Da Silva, A.; Guyon, L.; Djaker, N.; Josserand, V.; Neumann, E.; Bibette, J.; Vinet, F. Cyanine loaded lipid nanoparticles for improved in vivo fluorescence imaging. J. Biomed. Opt. 2009, 14 (5), 054005.

(33) Gravier, J.; Navarro, F.; Delmas, T.; Mittler, F.; Couffin, A. C.; Vinet, F.; Texier, I. Lipidots: a biocompatible alternative to quantum dots for in vivo fluorescence imaging. J. Biomed. Opt. 2011, 16 (9), 096013.

(34) Heurtault, B.; Saulnier, P.; Pech, B.; Proust, J.-E.; Benoit, J.-P. A novel phase inversion-based process for the preparation of lipid nanocarriers. Pharm. Res. 2002, 19 (6), 875-880.

(35) Jin, Z. H.; Josserand, V.; Foillard, S.; Boturyn, D.; Dumy, P.; Favrot, M. C.; Coll, J. L. In vivo optical imaging of integrin alpha(v)beta(3) in mice using multivalent or monovalent cRGD targeting vectors. Mol. Cancer 2007, DOI: 10.1186/1476-4598-6-41.

(36) Sancey, L.; Ardisson, V.; Riou, L. M.; Ahmadi, M.; Marti-Batlle, D.; Boturyn, D.; Dumy, P.; Fagret, D.; Ghezzi, C.; Vuillez, J. P. In vivo imaging of tumour angiogenesis in mice with the alpha(v)beta(3) integrin-targeted tracer Tc-99m-RAFT-RGD. Eur. J. Nucl. Med. Mol. Imaging 2007, 34 (12), 2037-2047.

(37) Delmas, T.; Couffin, A. C.; Bayle, P. A.; de Crécy, F.; Neumann, E.; Vinet, F.; Bardet, M.; Bibette, J.; Texier, I. Preparation and characterization of highly stable lipid nanoparticles with amorphous core of tuneable viscosity. J. Colloid Interface Sci. 2011, 360, 471-481.
(38) Delmas, T.; Piraux, H.; Couffin, A. C.; Texier, I.; Vinet, F.; Poulin, P.; Cates, M. E.; Bibette, J. How to prepare and stabilize very small nanoemulsions. Langmuir 2011, 27 (5), 1683-1692.

(39) Jacquart, A.; Kéramidas, M.; Vollaire, J.; Boisgard, R.; Pottier, G.; Rustique, E.; Mittler, F.; Navarro, F. P.; Boutet, J.; Coll, J. L.; Texier, I. LipImage 815: novel dye-loaded lipid nanoparticles for longterm and sensitive in vivo near-infrared fluorescence imaging. $J$. Biomed. Opt. 2013, 18 (10), 101311.

(40) Reulen, S. W. A.; Merkx, M. Exchange kinetics of proteinfunctionalized micelles and liposomes studied by Förster resonance energy transfer. Bioconjugate Chem. 2010, 21 (5), 860-866.

(41) Chen, H.; Kim, S.; He, W.; Wang, H.; Low, P. S.; Park, K.; Cheng, J.-X. Fast release of lipophilic agents from circulating PEGPDLLA micelles revealed by in vivo Förster resonance energy transfer imaging. Langmuir 2008, 24, 5213-5217.

(42) Chen, H.; Kim, S.; Li, L.; Wang, S.; Park, K.; Cheng, J.-X. Release of hydrophobic molecules from polymer micelles into cell membranes revealed by Förster resonance energy transfer imaging. Proc. Natl. Acad. Sci. U.S.A. 2008, 105 (18), 6596-6601.

(43) Lu, J.; Owen, S. C.; Shoichet, M. S. Stability of self-assembled polymeric micelles in serum. Macromolecules 2011, 44, 6002-6008.

(44) Skajaa, T.; Zhao, Y.; van den Heuvel, D. J.; Gerritsen, H. C.; Cormode, D. P.; Koole, R.; van Schooneveld, M. M.; Post, J. A.; Fisher, E. A.; Fayad, Z. A.; de Mello Donega, C.; Meijerink, A.; Mulder, W. J. M. Quantum dot and Cy5.5 labeled nanoparticles to investigate lipoprotein biointeractions via Förster resonance energy transfer. Nano Lett. 2010, 10 (12), 5131-5138.

(45) Jiwpanich, S.; Ryu, J.-H.; Bickerton, S.; Thayumanavan, S. Noncovalent encapsulation stabilities in supramolecular nanoassemblies. J. Am. Chem. Soc. 2010, 132 (31), 10683-10685.

(46) Ryu, J.-H.; Chacko, R. T.; Jiwpanich, S.; Bickerton, S.; Babu, R. P.; Thayumanavan, S. Self-cross-linked polymer nanogels: a versatile nanoscopic drug delivery platform. J. Am. Chem. Soc. 2010, 132 (48), 17227-17235.

(47) Chen, K.-J.; Chiu, Y.-L.; Chen, Y.-M.; Ho, Y.-C.; Sung, H.-W. Intracellularly monitoring/imaging the release of doxorubicin from pH-responsive nanoparticles using Förtser resonance energy transfer. Biomaterials 2011, 32, 2586-2592.

(48) Klymchenko, A. S.; Roger, E.; Anton, N.; Anton, H.; Shulov, I.; Vermot, J.; Mely, Y.; Vandamme, T. F. Highly lipophilic fluorescent dyes in nano-emulsions: towards bright non-leaking nano-droplets. RSC Adv. 2012, 2, 11876-11886.

(49) Wagh, A.; Qian, S. Y.; Law, B. Development of biocompatible polymeric nanoparticles for in vivo NIR and FRET imaging. Bioconjugate Chem. 2012, 23 (5), 981-992.

(50) Zhao, Y.; van Rooy, I.; Hak, S.; Fay, F.; Tang, J.; de Lange Davies, C.; Skobe, M.; Fisher, E. A.; Radu, A.; Fayad, Z. A.; de Mello Donegá, C.; Meijerink, A.; Mulder, W. J. M. Near-infrared fluorescence energy transfer imaging of nanoparticle accumulation and dissociation kinetics in tumor-bearing mice. ACS Nano 2013, 7 (11), 1036210370.

(51) Busch, C.; Schrôter, T.; Grabolle, M.; Wenzel, M.; Kempe, H.; Kaiser, W. A.; Resch-Genger, U.; Hilger, I. An in vivo spectral multiplexing approach for the cooperative imaging of different diseaserelated biomarkers with near-infrared fluorescent Förster resonance energy transfer probes. J. Nucl. Med. 2012, 53 (4), 638-646.

(52) Zou, P.; Chen, H.; Paholak, H. J.; Sun, D. Noninvasive fluorescence resonance energy transfer imaging of in vivo premature drug release from polymeric nanoparticles. Mol. Pharmaceutics 2013, $10,4185-4194$.

(53) Xia, Z.; Liu, Y. Reliable and global measurement of fluorescence resonance energy transfer using fluorescence microscopes. Biophys. J. 2001, 81 (4), 2395-2402.

(54) Weissleder, R. A clearer vision for in vivo imaging. Nat. Biotechnol. 2001, 19, 316-317.

(55) Delmas, T. Caractérisation physicochimique et compréhension des propriétés de vectorisation des nanoparticules lipidiques pour les applications biomédicales. Ph. D. thesis, Université Pierre et Marie Curie-Paris 6, 2011. 
(56) Göppert, T. M.; Müller, R. H. Protein adsorption patterns on poloxamer- and poloxamine-stabilized solid lipid nanoparticles (SLN). Eur. J. Pharm. Biopharm. 2005, 60, 361-372.

(57) Göppert, T. M.; Müller, R. H. Adsorption kinetics of plasma proteins on solid lipid nanoparticles for drug targeting. Int. J. Pharm. 2005, 302, 172-186.

(58) Mérian, J.; Boisgard, R.; Decleves, X.; Thezé, B.; Texier, I.; Tavitian, B. Synthetic lipid nanoparticles targeting steroid organs. J. Nucl. Med. 2013, 54 (11), 1996-2003.

(59) Bricarello, D. A.; Smolowitz, J. T.; Zivkovic, A. M.; German, J. B.; Parikh, A. N. Reconstituted lipoprotein: a versatile class of biologically-inspired nanostructures. ACS Nano 2011, 5 (1), 42-57.

(60) Jansch, M.; Stumpf, P.; Graf, C.; Rühl, E.; Müller, R. H. Adsorption kinetics of plasma proteins on ultrasmall superparamagnetic iron oxide (USPIO) nanoparticles. Int. J. Pharm. 2012, 428 (12), 125-133.

(61) Vonarbourg, A.; Saulnier, P.; Passirani, C.; Benoît, J. P. Electrokinetic properties of non charged lipid nanocapsules: influence of the dipolar distribution at the interface. Electrophoresis 2005, 26 (11), 2066-2075.

(62) Lainé, A. L.; Gravier, J.; Henry, M.; Sancey, L.; Béjaud, J.; Pancani, E.; Wiber, M.; Texier, I.; Coll, J. L.; Benoit, J. P.; Passirani, C. Conventional vs stealth lipid nanoparticles: formulation and in vivo fate prediction through FRET monitoring. J. Controlled Release 2014, $188,1-8$. 